\title{
Reflecting on a Decade of Women's Publications in Four Top Political Science Journals
}

Heather K. Evans, Sam Houston State University

A. Moulder, Sam Houston State University

ABSTRACT Publication in scholarly journals is a key to scholarly success. However, previous studies have shown that across many disciplines, including political science, women publish significantly less than men and prefer to use qualitative methodology. In this article, we explore the accuracy of these trends by examining a decade's worth (2000-o9) of women's publications in four top political science journals (the American Political Science Review, the American Journal of Political Science, the Journal of Politics, and PS: Political Science and Politics). Using a systematic content analysis, we determine the gender ratio of the authors, funding sources, methods, and the ratio of qualitative and quantitative studies. We find that while women publish less than men in each of these venues, their publication rates resemble their representation in the field.

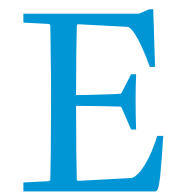

qual representation of women in the workplace is an issue that spans all disciplines and all venues. In academia, gender equality is important to the establishment of a diverse and well-balanced approach to research and intellectual exploration. Research demonstrates that women are leaving the political science workplace at a rate much higher than men (American Political Science Association [APSA] 2005). Furthermore, women are leaving the workplace mid-career at a rate two or three times that of men, sometimes called the "leaking pipeline" problem (APSA 2005).

In the social sciences and many other disciplines, publication in scholarly journals is viewed as key to one's scholarly successpublish or perish, as the old adage goes. Scholars are promoted and recognized on the basis of their written work (Guyer and Fidell 1973), in terms of both number and quality. For the health of the discipline, it is important to assess the journal publication playing field and determine whether it is level for both men and women.

Research regarding publication trends of men and women in multiple disciplines has shown that men consistently publish more than women (Breuning and Sanders 2007; Clemente 1973; Eigenberg and Baro 1992; Evans and Bucy 2010; Guyer and Fidell 1973; McGinty and Moore 2008; West, Newsom, and Fenaughty 1992;

Heather K. Evans is an assistant professor in the Department of Political Science at Sam Houston State University. Her research interests include political participation, public opinion, and political communication. She can be reached at hkeooz@shsu.edu. A. Moulder is a Masters student studying Public Administration at Sam Houston State University. Her research interests are human rights and international law.
Young 1995). However, most extant studies are dated and focus on only a few key variables. Very few compare women's publication rates with their representation in the field.

This article analyzes the presence of female authors in four of the top political science journals over the past decade (2000-09)the American Political Science Review (APSR), the American Journal of Political Science (AJPS), the Journal of Politics (JOP), and PS: Political Science and Politics (PS). In particular, we ask whether female authors differ from male authors in their presence as lead author, presence in multi-authored articles, funding, methodology, and general research approach. We conducted a systematic content analysis to determine the gender ratio of authors, their funding sources, their methods, and the ratio of qualitative and quantitative studies. This article presents an opportunity for the field to reflect on women's publication trends in four high-quality journals over the past decade and consider what we would like these trends to be.

\section{USING PUBLICATION RATES IS NOT ENOUGH!}

Publication rates alone are not enough to determine whether women are represented in any discipline. Most studies have shown that men publish more than women, but given that there are more men than women in many disciplines, this finding should not surprise us. Very few studies have assessed whether the trends are an accurate reflection of female representation in the field. In political science, only $17 \%$ of full professors and $26 \%$ of professors overall were women in 2006 (Sedowski and Brintnall 2007). Studies that have examined whether women are publishing at expected 
rates given their representation in political science have found mixed results.

Examining 15 political science journals from 1983-94, Young (1995) found that female authors were not well represented in scholarship, although female authorship increased throughout this period. In a follow-up study that examined the period of 19992004, Breuning and Sanders (2007) found that women were still not publishing in top journals at rates expected given their presence in the field; however, Evans and Bucy (2010) have shown that in certain subfields, women are publishing at a rate above their presence in the field. In their analysis of Political Communication and Press/Politics, Evans and Bucy (2010) also found that while women were less likely than men to appear as lead author, $39 \%$ of the articles in these journals were written by at least one female author, which was a higher percentage than their presence in the subfield of political communication. Because research on this topic is sporadic and publication rates are not fully documented, there is no real consensus as to whether women are publishing at rates proportionate to their presence in the field of political science.

Our analysis addresses several questions about female-authored publications in the field of political science. First, we determine the percentage of publications with female authors over the past decade (2000-09) in four of the top political science journals. We specifically address how often women appear as lead author and coauthor in each of these journals. Next, we compare their rates of publication within these journals to their presence in the field, as reported by the APSA. We explore whether the publication rates of women in these journals increased over this time period and whether the rates are consistent among the journals. We also examine whether female-authored work receives the same research support as male-authored work, and whether male and female scholars use different methodologies and general research approaches.

\section{METHOD}

\section{Journal Selection}

The APSR, AJPS, JOP, and PS were selected for analysis because of their recognition and prestige in the field. In 2009, three of these journals (APSR, AJPS, and JOP) were ranked in the top 10 journals by researchers in the field, according to the Journal of Citation Reports (Social Sciences Edition). While PS does not rank as highly as the other three, it is one of the most widely read journals in political science (Brandes et al. 2001). Each of these journals is read in all fields of political science and therefore draws from a wider pool of researchers than do journals that focus on a single subfield of political science.

\section{Sample and Coding Categories}

The sample for our study consisted of every issue of the APSR, AJPS, JOP, and PS from 2000 to 2009. All of the journals are quarterlies. We only included research articles subjected to peer review in our analysis. In all, we coded 1,88o articles: 428 from $A P S R, 521$ from AJPS, 613 from JOP, and 318 from PS. The coding instrument consisted of multiple categories, including author name, institutional affiliation, gender of lead author, gender ratio of authors for multi-authorship articles, general research type (qualitative, quantitative, a mixture of both, or synthesis of previous research), the data-gathering procedure (e.g., survey, content analysis, experiment), whether the researcher used original or secondary data (if the study used data), and whether the study received any type of funding.

\section{Figure 1}

\section{Percentage of Publications with a Female} Author in All Journals

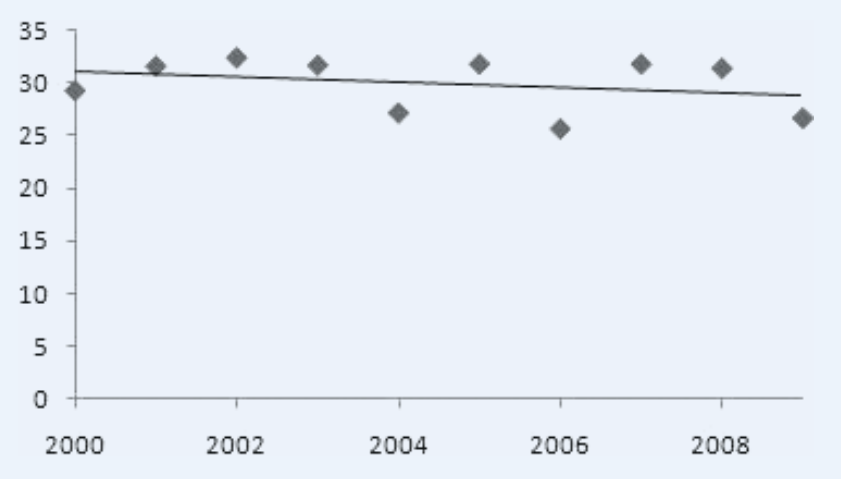

To determine gender, we searched for each author's name online, using his or her name and affiliation, until we found either an article mentioning the author's gender or a picture. The article was coded for the lead author's gender; the number of women appearing as authors for each publication; and, in cases of multiauthorship, the ratio of female to male authors (all males, all females, more men than women, more women than men, and 50/50). We also coded whether the names in multi-authored pieces were listed alphabetically.

In coding the articles' research type, we coded articles as qualitative if the information gathered on the target population was not given a numeric value. These studies were primarily interviews, participant observations, and focus groups. Articles were coded as quantitative if the method for gathering information about the population was represented numerically. These studies included mostly surveys and experiments. If more than one datagathering procedure was used, the article was coded as a "mixture of both." If no data-gathering procedure was used and the study was primarily a review of previous research, the article was coded as "synthesis of previous research."

In coding the data-gathering procedure, if the article went beyond synthesizing previous research, we coded whether the article used a survey (one-shot or secondary), an experiment, a content analysis, rational choice/formal models, interviews, a focus group, a case study, or participant observation. We also coded whether the author gathered the data or used secondary data.

Finally, we examined acknowledgments and credit lines to determine whether the research had been funded.

\section{FINDINGS}

To begin the analysis, it is important to present an overall picture of women's publications in the top political science journals. Overall, 553 research articles in our sample $(29.8 \%)$ had at least one female author. Only $20 \%$ of the articles appearing in these journals had female lead authors. ${ }^{1}$ Although men appeared as lead author in $80 \%$ of the articles, the percentage of studies with at least one female author seems promising, since Young (1995) found that only $24 \%$ of the articles in her study covering publications from 1983 and 1994 had at least one female author.

Surprisingly, in these journals, women did not appear as authors of published articles more in 2009 than they did in 2000 (see figure 1). In 2000, 29.3\% of articles in these journals had at 


\section{Figure 2}

\section{Percentage of Publications with a Female Lead Author in All Journals}

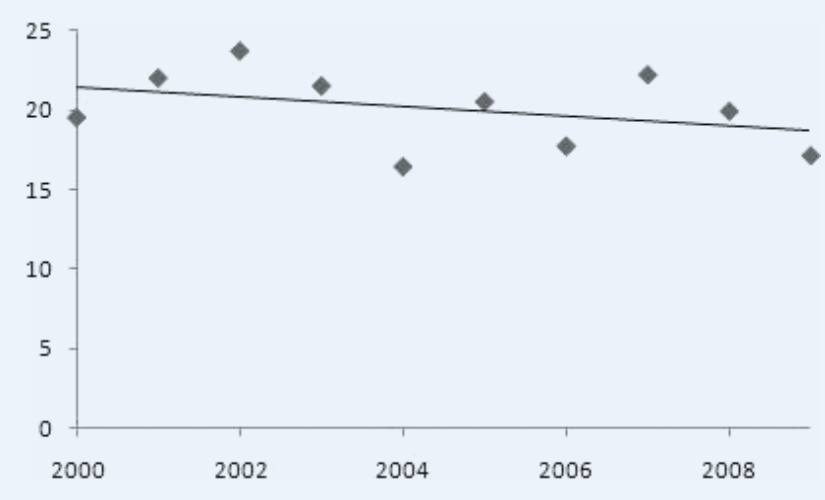

Figure 3

\section{Percentage of Female Publications in Each Journal}

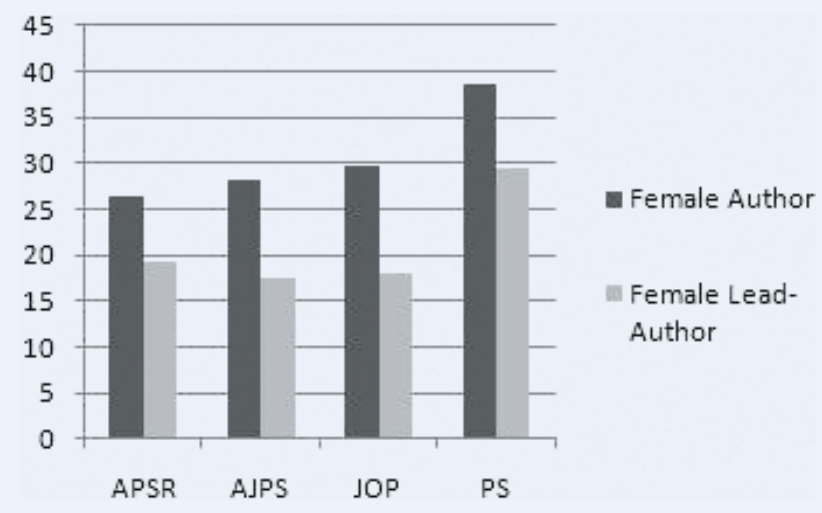

least one female author $(n=48)$. In 2009 , however, only $26.7 \%$ of articles had at least one female author $(n=53)$. The overall trend for the 10 years studied is a decline in female-authored publications; however, there were particular years (e.g., 2002) when more than $30 \%$ of articles had at least one female author.

The same trend is found for female-lead-author publications. When examining the percentage of female-lead-author publications in 2000 and 2009, we found that women were listed as lead authors in $\mathbf{2} \%$ fewer articles in 2009 (see figure 2 ). Women were listed as a lead author in $19.5 \%$ of the articles in $2000(n=32)$ but only $17.1 \%$ of the publications in $2009(n=34)$. As our results in figure 1 show, there were certain years in which the percentage of female-lead-author publications was more than 20, but overall, the percentage of female-lead-author publications within these journals declined.

When examining the journals separately, we found that PS publishes significantly more articles $(p \leq .01)$ featuring female authors than the other three journals (see figure 3 ). ${ }^{2}$ From 2000 to 2009, $38.5 \%$ of the pieces published in $P S$ had at least one female author, and $29.4 \%$ of the articles featured a female lead author. JOP had the second highest percentage of articles featuring at least one female author (29.7\%), while the APSR had the lowest percentage (26.4\%). The APSR did, however, have the second high-

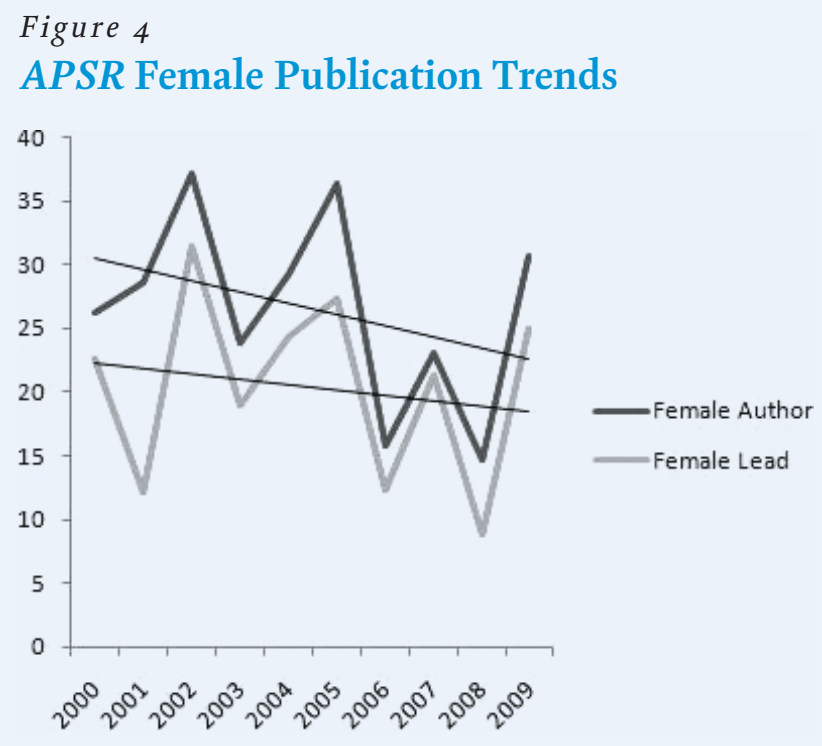

Figure 5

AJPS Female Publication Trends

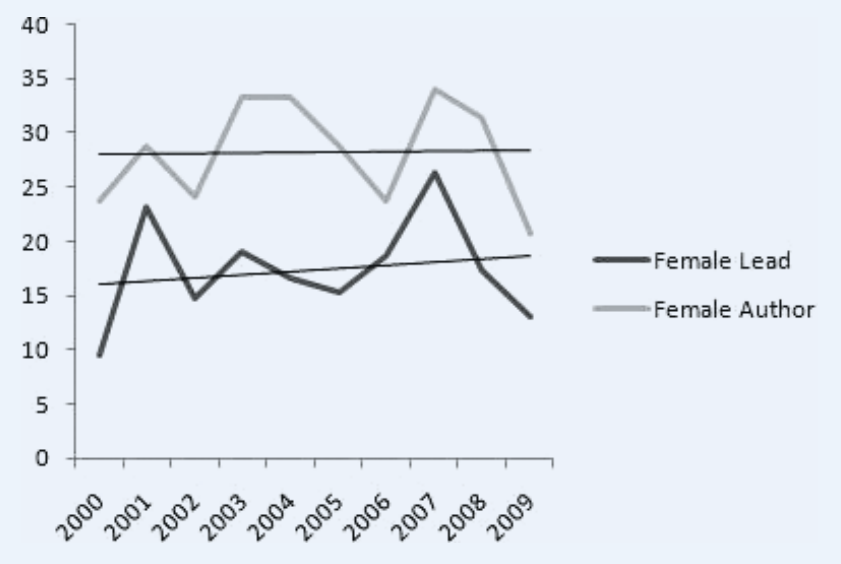

est percentage of female-lead-author publications (19.2\%), followed by JOP (18\%) and AJPS (17.5\%).

Examining year-by-year data, we found that while the overall trend is down, the number of female-authored pieces increased in certain journals. Figure 4 shows the trend in both female-leadauthor publications and publications featuring at least one female author in the APSR over the 10-year time frame. In 2009, more pieces were published with a female author than in 2000, but the downward trend persists. The same is true for publications featuring a female lead author. In 2000, $22.6 \%$ of the articles published in the APSR featured a female lead author, while in 2009, $25 \%$ of the articles had a female lead author. In 2002, the APSR featured significantly more female-lead-author publications (31.4\%) than in any other year. The percentage of pieces published in 2009 with at least one female author was $30.6 \%, 12.5 \%$ higher than the number of female-authored publications 15 years prior (Young 1995).

Over the 10-year time frame, AJPS had fairly stable results. The percentage of pieces with at least one female author hovered around $28 \%$ (see figure 5). There was also a slight increase in the percentage of pieces published in AJPS with a female lead author. 
Figure 6

JOP Female Publication Trends

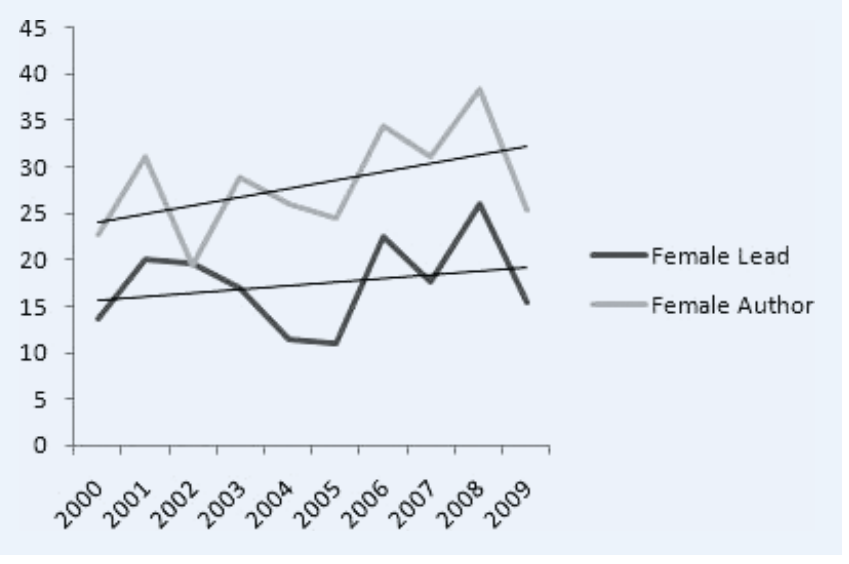

Figure 7

PS Female Publication Trends

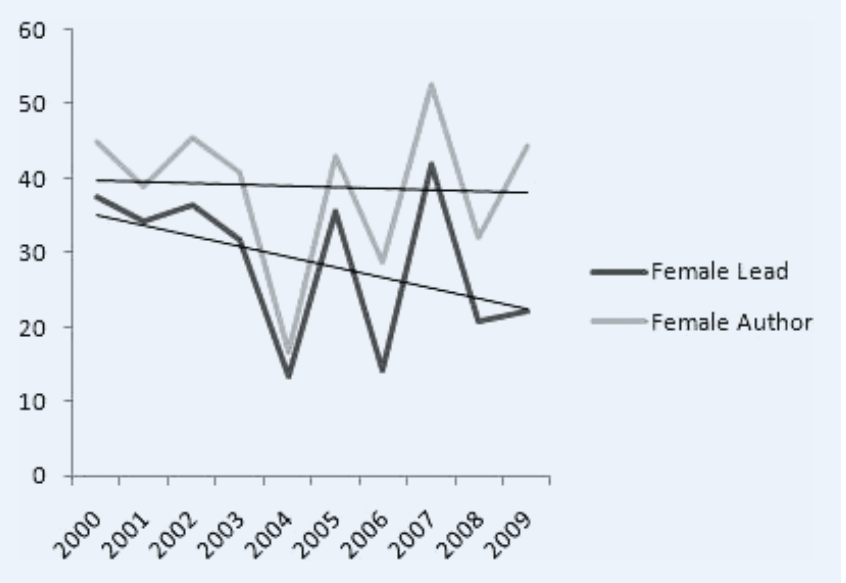

In 2000, only $9.5 \%$ of the articles featured a female lead author, while in $2009,13 \%$ featured a female lead author.

As figure 6 shows, there have been more articles with female authors and female lead authors over the 10-year time frame in JOP than in AJPS. In 2000 , only $13.6 \%$ of the pieces published in JOP had a female lead author, but in $2009,15.4 \%$ had a female lead. Over $25 \%$ of the pieces in 2009 had at least one female author, while only $22.7 \%$ in 2000 had the same. The high point for female publications in JOP was in 2008 , when $25.9 \%$ of the pieces had a female lead author and $38.3 \%$ featured at least one female author.

As we mentioned earlier, $P S$ published significantly more female-authored pieces than any other journal in the sample over this time frame. As figure 7 shows, the percentage of femaleauthored publications that appeared in $P S$ between 2000 and 2009 remained fairly constant. In contrast, female-lead-author publications decreased over the 10-year span, from $37.5 \%$ in 2000 to $22.2 \%$ in 2009. The year with the most female-authored publications was 2007 (52.6\%).

We also examined multiple authorship rates to assess whether female scholars differed from male scholars in terms of collaborations. In our sample, $54.2 \%(n=1,019)$ of articles were published by more than one author. Of those publications, male-only collaborations were most common (see figure 8 ). Only $4 \%$ of the collaborations were between women only $(n=41)$. Female-only collaborations were less likely to appear in the APSR than in the other three journals $(n=8)$.

Like Fisher et al. (1998), we found that the most common form of authorship for men in these journals was single authorship or same-sex collaboration. More than $70 \%$ of the articles published in these journals featured only male authors; that is, seven out of every 10 articles were written by either a single male author or a male-only collaboration. Men were just as likely to publish independently ( $n=651)$ as with other men $(n=658)$. Women, on the other hand, were more likely to publish with men $(n=320,58.1 \%)$ than independently $(n=190,34.5 \%)$ or with other women $(n=41$, $7 \cdot 4 \%)$.

Next, we examined whether women were represented in these journals in proportion to their presence in the field. According to the APSA, in 2006, women made up approximately $26 \%$ of the political science discipline (Sedowski and Brintnall 2007). Using this percentage as a baseline comparison, it is clear that women are not appearing as authors in most of these journals at a rate comparable to their presence in the field. Overall, women only appeared as lead authors in $20 \%$ of the publications in our sample between 2000 and 2009, a number that is somewhat inflated by the rate of female-lead-author publications that appeared in $P S{ }^{3}$ An examination of the percentage of pieces published with at least one female author paints a less depressing picture. On average, women appeared in $29.8 \%$ of the publications.

To assess whether women and men are receiving the same type of financial support, we coded whether the author(s) mentioned funding in their acknowledgement and credit lines. We found that a higher percentage of the articles with a female lead author received funding than articles without a female lead author. Overall, $31.8 \%$ of the articles published in these four journals received funding. Of all studies with a female lead author, $35 \%$ received funding, compared to only $31 \%$ of the male-lead-authored papers $(p \leq .05)$. When comparing the rates of funding for multiauthored papers, we found that $41.9 \%$ of all publications with at least one female contributor received funding, whereas only $33.5 \%$ of male-only collaborations received funding $(p \leq .05)$. Femaleauthored research reported funding more often than did malepublished research.

Finally, we examined whether women and men differ in their methods or general research approach. Female and male lead authors specified methods at similar rates. Of those articles written by a female lead author, $87.8 \%$ specified a method, while $86 \%$ of male-lead-author publications did the same. The types of methods used by each gender were also very similar. Both male and female lead authors used content analyses most often, followed by multi-methods approaches, extended literature review and synthesis, surveys, and case studies (see table 1).

Previous research has found that women tend to publish more qualitative pieces and men publish more quantitative research (Evans and Bucy 2010). We found that in our sample, articles written by female lead authors were significantly more likely to be qualitative (24.3\%) than were articles written by male lead authors $(18.8 \%)(p \leq .05)$. Almost three-quarters of the articles with a female lead author were strictly quantitative or a mixture of both quantitative and qualitative approaches (74.3\%). Approximately $77 \%$ of articles overall (both female and male lead authors) used data in their analysis. Of those that used data, female lead authors were more likely to use original data $(n=107,39 \%)$ than were 


\section{Figure 8}

\section{Gender Ratio of Multi-Authored Papers}

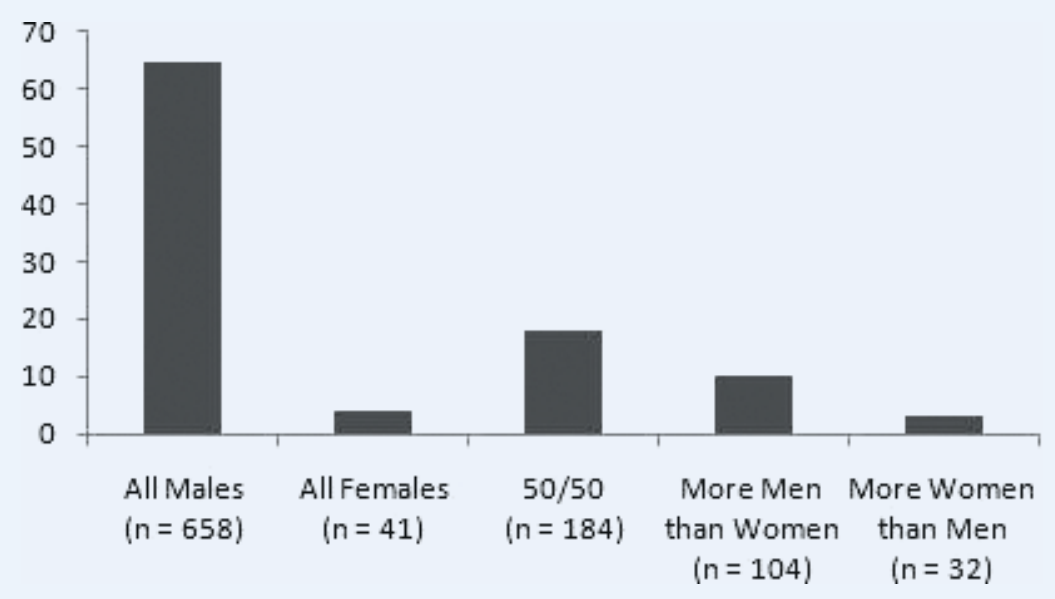

standards as their male counterparts at research universities, this $20 \%$ lead author percentage is troubling. The percentage of articles featuring a female lead author is not proportionate with their presence in the field. Women are also not publishing alone as often as men. When examining the rates of single-authorship and multiauthorship, we find that women are more likely to publish with men $(58.1 \%)$ than with other women $(7.4 \%)$ or by themselves $(34.5 \%)$. These figures seem to suggest that perhaps women are not fully integrated into the discipline, although some scholars have argued that collaboration is a key sign of female integration (Mackie 1985). Our analysis cannot say definitively which line of reasoning is correct. If collaborative research is respected and positively evaluated by the field, then the percentage of pieces featuring at least one female author is an encouraging sign for the discipline.

The percentage of women in the field of political science may not be the best comparison to use with these particular journals. As Evans and Bucy state: 'To truly examine the 'representation' of women in publication, one needs to carefully assess what the productivity rates of female scholars should be within journals" $(2010,301)$. Since these are four of the most prestigious and/or recognized journals in political science, their authors usually come from research universities. The general preconception is that women are less likely to actively seek positions at these universities because of other influences in their lives, such as the desire to start a family. Recent research, however, has revealed that there are no differences between the types of institutions where men and women find positions (Lopez 2003). It would be useful to compare the percentage of articles written by women within these journals to the percentage of women who hold faculty positions at research universities, and to perform a survey of women in the field to determine why they do or do not submit their work to particular journals.

In terms of financial support for research, publications featuring at least one female author tend to report funding more often than publications featuring only men. Significantly more studies with female lead authors report funding than do studies with male lead authors, illustrating that women in the discipline are conducting relevant, reliable, and valuable research. Unlike previous research that shows women write fewer grant proposals and are less successful acquiring research funds, this study shows that at least in these four journals, female-published research has received more funding (Waisbren et al. 2008).

The type of research differed very little between the two genders. Methodologically, both men and women used content analyses most often, followed by multi-methods approaches, one-shot surveys, extended literature reviews, and case studies. Female lead authors were more likely to use qualitative methods than were male lead authors, but almost two-thirds of articles with a female lead author included quantitative methods. Women were also just as likely as men to use data in their analyses, and were more likely to report using an original dataset, although the difference was not significant.

Were the pieces published by female authors dominated by a few key political scientists? If this is the case, then the percentage three journals featured a female lead author (APSR, $19.16 \%$, AJPS, $17.48 ; J O P, 17.96)$. Given that we hold women to the same research 
of publications by at least one female author may not be as encouraging as we would prefer. According to our results, 296 female authors published as a lead author in these four journals over the past 10 years, and $25 \%$ were listed as lead author more than once $(n=76)$. A few of the female lead authors had more than five publications during this time. Comparing these rates to the authorship rates in Evans and Bucy's (2010) study of the subfield of political communication, we find a significantly higher percentage of repeat author publications within these top political science journals. While some female scholars publish frequently in these top journals, they do not dominate them, which is a positive sign for gender representation in publication. ${ }^{4}$

Although our study provides some important insights into the rates of publication by women in the field, work remains to be done. To truly examine the representation of women in political science scholarship, we need to determine whether publication as a co-author is as highly regarded in the discipline as publication as lead author. If we value co-authorship, our study yields positive results. Women are at least appearing in publications similar to their presence in the field. If being listed as lead author carries more (or even all) weight, then women are not publishing in these journals at rates expected, given their representation in the field.

\section{NOTES}

A version of this paper was presented at the 2011 annual meeting of the Western Political Science Association, San Antonio, TX.

1. Of the articles that had a female author but not a female lead author, $61.8 \%$ listed authors' names alphabetically.

2. Using independent groups t-test: $P S$ and $A P S R, p \leq .01 ; P S$ and $J O P, p \leq .01 ; P S$ and $A J P S, p \leq .01$.

3. Female lead authors appeared in $19 \%$ of the pieces published by the APSR, $18 \%$ of the pieces in JOP, $17 \%$ of the pieces in AJPS, and $29 \%$ of the pieces in PS.

4. Comparing these results to male-lead-author publications, we found that 993 men published as lead author in these four journals, and $27.8 \%$ published more than once. A total of 1,488 journal articles were published by a male lead author, and over half of those articles were published by repeat authors.

\section{REFERENCES}

American Political Science Association (APSA). 2005. "Women's Advancement in Political Science: A Report of the APSA Workshop on the Advancement of
Women in Academic Political Science in the United States." http://www. apsanet.org/imgtest/womeninpoliticalscience.pdf.

Brandes, Lisa, Eloise Buker, Susan Burgess, Constance Cook, Janet Flammang, Shirley Geiger, Susan Okin, Bang-Soon Yoon, and Martha Ackelsberg. 2001. "The Status of Women in Political Science: Female Participation in the Professoriate and the Study of Women and Politics in the Discipline." PS: Political Science and Politics 34 (2): 319-26.

Breuning, Marijke, and Kathryn Sanders. 2007. "Gender and Journal Authorship in Eight Prestigious Political Science Journals." PS: Political Science and Politics 40: $347-51$.

Clemente, Frank. 1973. "Early Career Determinants of Research Productivity." American Journal of Sociology 79 (2): 409-19.

Eigenberg, Helen, and Agnes Baro. 1992. "Women and the Publication Process: A Content Analysis of Criminal Justice Journals.” Journal of Criminal Justice Education 3 (2): 293-314.

Evans, Heather K., and Erik P. Bucy. 2010. “The Representation of Women in Publication: An Analysis of Political Communication and the International Journal of Press/Politics." PS: Political Science and Politics 43: 295-301.

Fisher, Bonnie S., Craig T. Cobane, Thomas M. Vander Ven, and Francis T. Cullen. 1998. "How Many Authors Does It Take to Publish an Article? Trends and Patterns in Political Science." PS: Political Science and Politics 31 (4): 847-56.

Guyer, Larue, and Linda Fidell. 1973. "Publications of Men and Women Psychologists: Do Women Publish Less?” American Psychologist 28 (2): 157-6o.

Lopez, Linda. 2003. "Placement Report: Political Science Ph.D.s and ABD's on the Job Market in 2001-2002." PS: Political Science and Politics 36 (3): 824-30.

Mackie, Marlene. 1985. "Female Sociologists' Productivity, Collegial Relations, and Research Style Examined through Research Publications." Sociology and Social Research 69: 189-209.

McGinty, Stephen, and Anne C. Moore. 2008. "Role of Gender in Reviewers' Appraisals of Quality in Political Science Books: A Content Analysis." Journal of Academic Librarianship 34 (4): 288-94.

Sedowski, Leanne, and Michael Brintnall. 2007. "Data Snapshot: The Proportion of Women in the Political Science Profession." https://www.apsanet.org/ imgtest/Website\%2obrief\%20on\%2owomen\%2oin\%2oPS\%20v2\%201\%202007. pdf

Waisbren, Susan A., H. Bowles, T. Hasan, K. H. Zou, S. J. Emans, C. Goldberg, et al. 2008. "Gender Differences in Research Grant Applications and Funding Outcomes for Medical School Faculty." Journal of Women's Health 17 (2): 207-14.

West, Stephen G., Jason T. Newsom, and Andrea M. Fenaughty. 1992. "Publication Trends in JPSP: Stability and Change in Topics, Methods, and Theories across Two Decades." Personality and Social Psychology Bulletin 18: 473-84.

Young, Cheryl D. 1995. "An Assessment of Articles Published by Women in 15 Top Political Science Journals." PS: Political Science and Politics 28 (3):525-33. 